Society for the Anthropology of Work • Book Forum: Threshold

\title{
Reflections on Binational Emergency Workers in the Midst of the Pandemic
}

leva Jusionyte

Published on: Jul 05, 2021

License: Creative Commons Attribution 4.0 International License (CC-BY 4.0). 
Thank you, Elisabetta Campagnola, Lawrence Ramirez, Rebecca Richart, and Ishani Saraf, for such a generous and thoughtful engagement with the stories, experiences, and arguments presented in my ethnography Threshold: Emergency Responders on the US-Mexico Border. During the COVID-19 pandemic, our public conversations have turned to "frontline" personnel and "essential" workers, categories of people that, we soon came to recognize, include not just doctors and nurses, paramedics and firefighters and police officers, but everyone whose job does not allow for staying at home and working remotely: bus drivers, grocery store clerks, plumbers, electricians, and janitors. For some of these essential workers, like the paramedics and EMTs at the center of my book, there is and can be no "social distancing" unless it is the kind that is enforced by border politics.

It is not surprising that the pandemic has exposed further seams in already questionable and violent ways that the U.S. government tries to control, in the name of security, the border with Mexico. With COVID-19 cases rising in the United States, an order issued on March 21, 2020 restricted "non-essential" northbound traffic from Mexico. This border closure did nothing to stop the southbound spread of the virus, at a time when mostly volunteer emergency responders and overburdened medical personnel at public hospitals, short on everything from masks to ventilators in ordinary times, struggled to save their patients and to survive themselves. Following the news from my home in Massachusetts, I was sad and angry to learn how one after another of the emergency responders I had worked with in Nogales, as well as their families, fell ill. Like the wounds experienced by migrants that I document in Threshold, these are not accidents, but results of neglect and underfunding by the Mexican government and what, in his contribution to this forum, Lawrence Ramirez describes as the "obstructions" of border emergency response in the United States, which refuses to accept that in border towns, public health, as a core dimension of public safety, is a binational matter.

Although emergency responders were exempt from border closure and, at least officially, could go across, in practice their ability to work together serving communities on both sides of the border was severely curtailed. As Elisabetta Campagnola notes in her contribution, this binational partnership draws from "a sense of the local that cannot be completely compromised by the state project." Closing the border during the pandemic, as with the militarization and fortification called for by the national security agenda I discuss in the book, has demonstrated yet again how the federal state tries to impose policy priorities that are askew with local realities. This is 
the "constructed nature of emergencies" that, as Ishani Saraf points out, are "produced by the material and metaphorical effects of the border." In binational communities like Nogales, what comes from the other side is not a threat (whether understood as unauthorized migrants or drugs or infectious pathogens), but help, in the form of mutual aid shared between emergency workers, the ones who are the first to respond to fires, floods, toxic spills, heart attacks, snake bites, and other lifethreatening situations and conditions. The jurisdictional line, reinforced with a steel and cement wall, not only causes injury, but also limits rescue.

The vantage point of emergency responders allowed me to explore what Rebecca Richart calls "the life-or-death effects of fluidity or restriction on the border." Today, over a year into the pandemic, with the border still closed, the numbers show an enormous gap between high vaccination rates in southern Arizona and vaccine shortages in northern Sonora, where even emergency responders are still awaiting their turn. As far as the broader issues of violence and caregiving in the borderlands, nothing has changed since I conducted my fieldwork half a decade ago: the Border Patrol's tactical infrastructure, including the wall, now both longer and taller, is still in place; migrants and refugees, more of them stranded for months and even years awaiting their turn to ask for asylum, still get wounded and die when trying to climb the fence or walk around it. And emergency responders, whether they are employed by local governments or volunteer with humanitarian aid organizations, continue their essential work of aid and rescue, as made more difficult by policies that further restrict their activities.

Reflecting on Threshold in the times of COVID-19, I am disappointed, though not surprised, by the disregard for local realities of entanglement and interdependence in the disruption of cross-border ties that bind these towns together. Far from mitigating it, border politics exacerbated the toll of the pandemic on binational communities and the frontline emergency workers who serve them, putting the health and life of residents on both sides at increased risk. This, too, is not accidental. It doesn't have to be this way.

\section{Author Bio}

Ieva Jusionyte is Watson Family University Associate Professor of International Security and Anthropology at Brown University. Her research on the U.S.-Mexico border was supported by the National Science Foundation and the Wenner-Gren Foundation. In addition to her work as a scholar, she spent five years volunteering as 
an emergency medical technician, paramedic, and wildland firefighter in Florida, Arizona, and Massachusetts. 